\title{
Salmonella Typhimurium Brain Abscess in an Immunocompetent Adult with a Spontaneous Intracerebral Hemorrhage: A Case Report
}

\author{
Gyu-Sung Kang, Ha-Young Choi, Jung-Soo Park, Eun Jeong Koh, Jong-Myong Lee
}

Department of Neurosurgery, Research Institute of Clinical Medicine of Chonbuk National University, Biomedical Research Institute of Chonbuk National University Hospital, Jeonju, Republic of Korea

Corresponding author: Jung Soo Park Department of Neurosurgery,

Chonbuk National University Hospital,

Chonbuk National University, 20,

Geonjiro Deokjin-gu, Jeonju 54907,

Republic of Korea

Tel: $+82-63-250-1870$

Fax: +82-63-277-3273

E-mail: rollingstone12@hanmail.net

Received: June 26, 2020

Revised: August 2, 2020

Accepted: August 19, 2020

\begin{abstract}
A brain abscess caused by Salmonella typhimurium (S. typhimurium) in an immunocompetent adult is rare. We report a case of brain abscess caused by $S$. typhimurium in a 46-year-old male and a brief review of the literature. The patient visited a local hospital because of right hemiparesis. Brain computed tomography and magnetic resonance imaging results showed an acute hematoma in the left basal ganglia. After 3 weeks of conservative therapy, the patient was transferred to our hospital due to uncontrolled fever, aphasia, and aggravated motor weakness. Contrast-enhanced computed tomography showed a rim-enhanced cystic mass with peripheral edema, prompting trephination to drain the cystic fluid. The drained fluid was yellowish-mucoid, similar to a pus. Specimens from the drained fluid and urine S. typhimurium were cultured and microbiologically analyzed. We administered ceftazidime $2,000 \mathrm{mg}$ and vancomycin 2,000 mg/day for 6 weeks intravenously and changed ceftriaxone 2,000 $\mathrm{mg} /$ day for an additional 3 weeks due to a drug eruption. The patient recovered with no neurological deficits. Surgical drainage of the intracranial abscess and prolonged sensitive antibiotic therapy is essential to obtain positive results.
\end{abstract}

Key Words: Brain abscess; Intracerebral hemorrhage; Salmonella typhimurium

\section{INTRODUCTION}

Although Salmonella species can cause focal subdural or epidural empyema and brain abscesses in any age group, most reported cases are patients with precipitating factors, such as immunocompromised conditions (e.g., human immunodeficiency virus [HIV] infection, chemotherapy, long-term steroid therapy), blood problems (e.g., sickle cell disease), previous brain surgery or infarcted brain tissue, hepatic or gastrointestinal disease, alcohol abuse, or infancy ${ }^{1,3,5,7,8,11,13,15)}$. Intracerebral infections caused by Salmonella are rare. Here, we present a rare case of an intraparenchymal brain abscess caused by Salmonella typhimurium ( $S$. typhimurium) at the site of a liquefied intracerebral hemorrhage (ICH)

\section{CASE REPORT}

A 46-year-old man visited a local hospital because of rightsided weakness. On neurological examination, the patient showed right hemiparesis and mild dysarthria. Brain computed tomography (CT) and magnetic resonance imaging (MRI) sho- wed acute ICH in the left basal ganglia (Fig. 1). The patient was treated with mannitol alone, and his neurological symptoms were not aggravated. On the $23^{\text {rd }}$ day of admission, the patient suffered from malaise and a severe headache. On the $25^{\text {th }}$ day, he was referred to our hospital because of uncontrolled fever, aggravated hemiparesis, and motor aphasia. A follow-up enhanced brain CT scan revealed a rim-enhancing hypodense lesion and massive peri-lesional edema (Fig. 2A). We performed an emergency trephination to drain the cystic mass lesion in the left basal ganglia. The drained fluid was not a chronic liquefied hematoma; instead, it was yellowish-mucoid in nature and gave a characteristic odor when it was an abscess. After the operation, we rechecked the brain MRI and suspected an intracerebral abscess (Fig. 2B, C). The patient had been healthy prior to the occurrence of spontaneous $\mathrm{ICH}$. He did not have gastrointestinal symptoms, meningeal signs, or immunocompromised indications. The results of the blood examination were white blood cell (WBC) $14,300 / \mu$, C-reactive protein (CRP) $72.98 \mathrm{mg} / \mathrm{L}$, erythrocyte sedimentation rate (ESR) 73 $\mathrm{mm} / \mathrm{hr}$, hemoglobin $13.4 \mathrm{~g} / \mathrm{dL}$, platelets $164,000 / \mu \mathrm{L}$, and HIV $\mathrm{Ab}(-)$. Evaluation of the cerebrospinal fluid revealed the following values: WBCs, $2 / \mathrm{mm}^{3}$ with $0 \%$ neutrophils and $0 \%$ lymphocytes, red blood cells, $71 / \mathrm{mm}^{3}$, glucose, $75 \mathrm{mg} / \mathrm{dL}$, pro- 
tein, $31.1 \mathrm{mg} / \mathrm{dL}$, and no growth on culture.

On microbiological analysis, $S$. typhimurium was cultured from the pus and urine (Fig. 3). In the blood culture, there was no growth of bacteria. Microbes were identified as Salmonella group using the Vitek $2 \mathrm{XL}$ system (bioMérieux, Nürtingen, Germany), and the serotype was identified as $S$. typhimurium using Salmonella antisera (JoongKyeom, Ansan, Korea). We administered ceftazidime 2,000 mg and vancomycin 2,000 mg/day for 6 weeks via an intravenous route based on the antimicrobial susceptibility test (Table 1) and changed ceftriaxone 2,000 mg/ day for an additional 3 weeks due to the occurrence of a drug eruption caused by vancomycin.

The patient recovered normal neurological status, and followup ESR/CRP conducted at week 9 of hospitalization was normalized (Fig. 4). Follow-up at one year after MRI showed only focal encephalomalacia in the left basal ganglia and temporal area (Fig. 5).
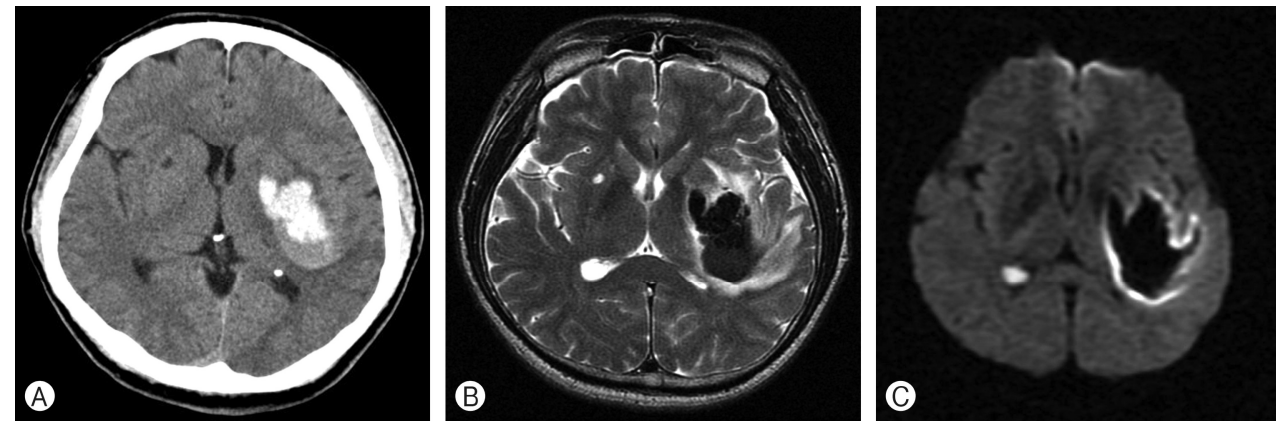

Fig. 1. Brain computed tomography (CT) and magnetic resonance imaging (MRI) from a local hospital. The brain CT showed a hyperdense lesion on the left basal ganglia (A), and a MRI scan (T2-weighted, diffusionweighted, axial section) showed hypointensity in the same area $(B, C)$ consistent with an acute hematoma.
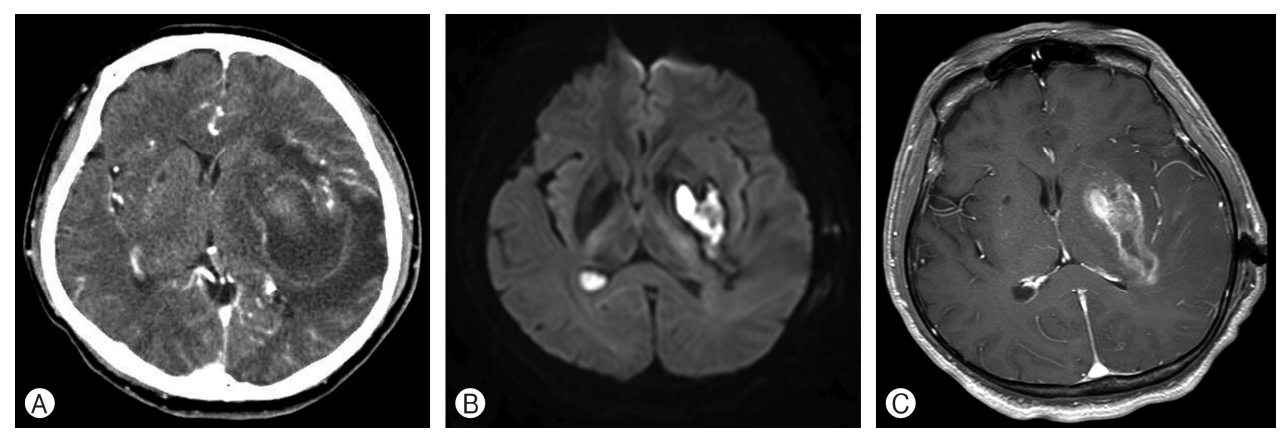

Fig. 2. Enhanced brain computed tomography (CT) and magnetic resonance imaging (MRI) at our hospital. A rim-enhancing hypodense lesion and perilesional edema were found on enhanced CT (A). The postoperative MRI diffusion-weighted image showed a hyperintense lesion (B) and $T 1$ enhanced image showed ring-enhanced lesion $(C)$ in the same area, suspicious for a brain abscess.
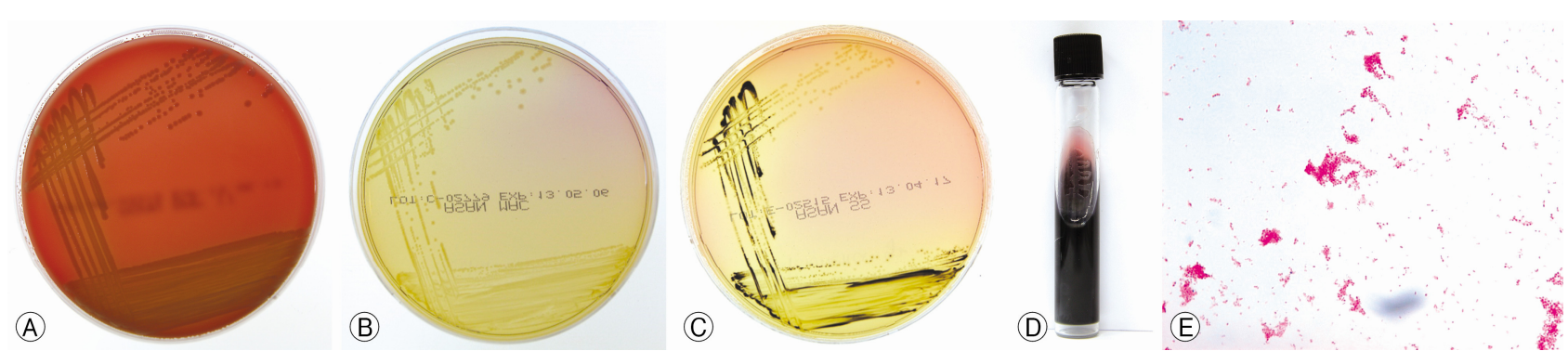

Fig. 3. Round, gray colonies on a $5 \%$ sheep blood agar plate (A), and colorless colonies on a MacConkey agar plate (B) were observed at $24 \mathrm{hr}$ incubation at $37^{\circ} \mathrm{C}, 5 \% \mathrm{CO}_{2}$ conditions. It produced hydrogen sulfide on a Salmonella-Shigella Agar plate (C) and showed a red slant/yellow bottom (alkali/acid reaction) with hydrogen sulfide in triple sugar iron agar (D). Gram-negative bacilli from a blood agar plate (Gram stain, ×1,000 magnification) (E). 


\section{DISCUSSION}

Intracranial infections (meningitis, subdural or epidural empyema, brain abscess) caused by Salmonella species are very rare. Since the first Salmonella brain abscess was reported by McClintock in an autopsy study in 1902, fewer than 100 cases of intracranial Salmonella infections have been reported $^{18,19,22)}$. Among intracranial infections, brain abscesses remain the rarest, and, to our knowledge, only 12 cases of brain abscess caused by $S$. typhimurium have been reported (Table $2)^{3,6,7,10-13,16,19,21,23)}$. However, intracranial infections associated with Salmonella species have increased recently because of the number of immunocompromised patients with acquired immunodeficiency syndrome (AIDS), corticosteroid therapy, broad-spectrum antibiotic use, or chemotherapy has been increasing ${ }^{13,22)}$. Although intracranial Salmonella infections can occur at any age, they tend to be more common in infancy because of the immunologically naïve state ${ }^{13,16,19)}$.

According to Mahapatra and Bhatia, infectious routes for brain abscesses caused by Salmonella can be divided into 3 groups $^{17)}$. First, patients develop a brain abscess during a Salmonella infection elsewhere in the body. Second, patients have a history of Salmonella infection. In the third group, patients presented with a brain abscess with no apparent history of salmonellosis. Our patient had no history of Salmonella infection. Although $S$. tiphymurium was cultured from his urine and drained pus, his blood culture was negative. The patient did not suffer from gastrointestinal symptoms and had no risk factors for decreased immunity.

Intracranial Salmonella infections tend to involve diseased tissues, such as hematomas, fractures, and neoplasms ${ }^{22)}$. In our case, diseased tissue and liquefied hematoma may have acted as the culture medium. Systemic diseases including malaria, sickle cell anemia, diabetes mellitus, AIDS, systemic lupus erythematosus, hepatic disease, gastrointestinal disease, alcohol abuse, corticosteroid therapy, and chemotherapy are other factors associated with salmonellosis ${ }^{8,11,13)}$. In addition, focal infections adjacent to the brain, such as otitis, paranasal sinus infection, meningitis, and osteomyelitis of the skull, are other precipitating factors ${ }^{22}$. In the previous literature on $S$. typhimurium brain abscesses, 3 cases presented with focal infections adjacent

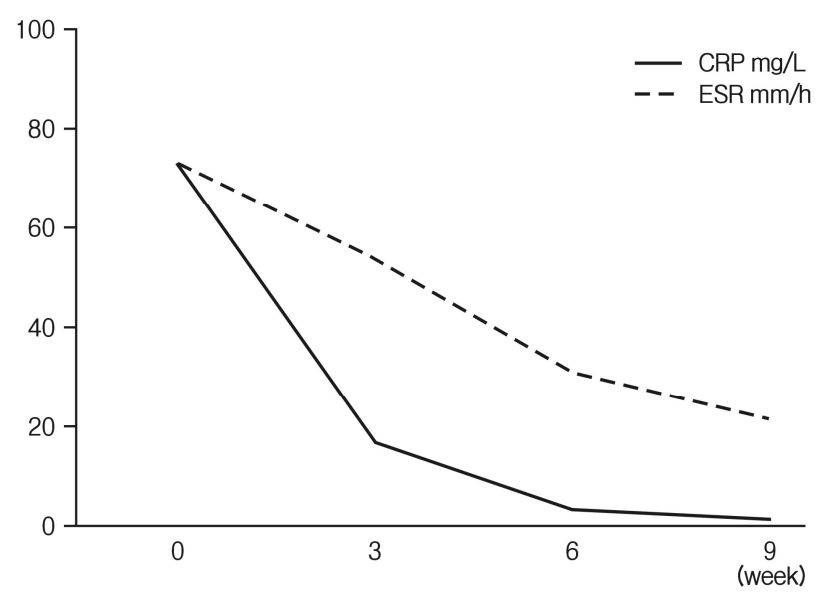

Fig. 4. Follow-up erythrocyte sedimentation rate (ESR), C-reactive protein (CRP).
Table 1. Antibiotics sensitivity test

\begin{tabular}{lcc}
\hline \hline Antibiotics & Interpretation & $\mathrm{MIC}(\mathrm{mg} / \mathrm{mL})$ \\
\hline Ampicillin/Sulbactam & Sensitive & $\leq 2$ \\
Amikacin & Resistant & $\leq 2$ \\
Cefazolin & Resistant & $\leq 4$ \\
Cefepime & Sensitive & $\leq 1$ \\
Cefoxitin & Resistant & $\leq 4$ \\
Levofloxacin & Sensitive & 1 \\
Meropenem & Sensitive & $\leq 0.25$ \\
Trimethoprim/Sulfamethoxazole & Sensitive & $\leq 20$ \\
Cefotaxime & Sensitive & $\leq 1$ \\
Ceftazidime & Sensitive & $\leq 1$ \\
Piperacillin/Tazobactam & Sensitive & $\leq 4$ \\
\hline
\end{tabular}

$\mathrm{MIC}$, minimum inhibitory concentration.
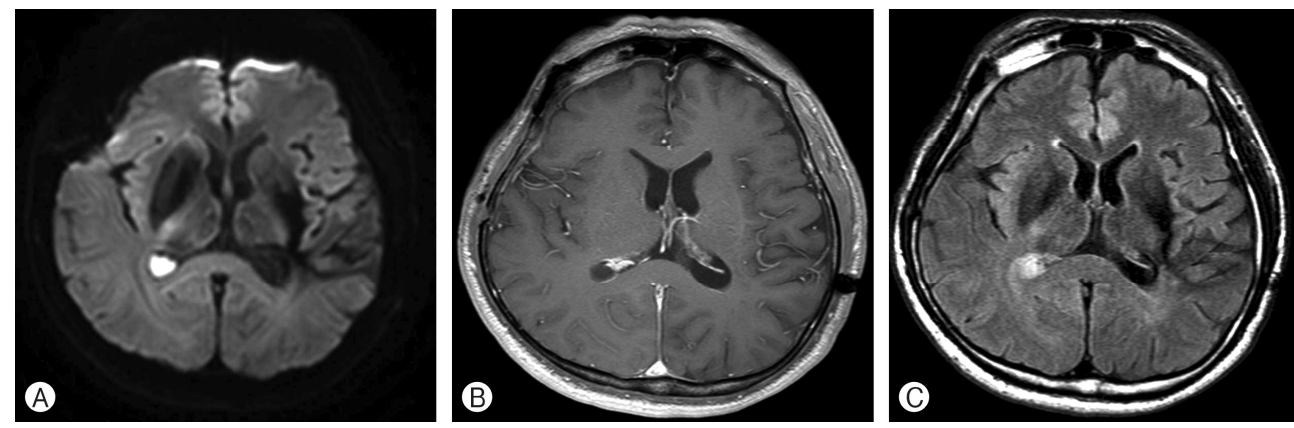

Fig. 5. Follow-up magnetic resonance imaging showed only focal encephalomalacic change on the left basal ganglia and temporal area (A, diffusion-weighted imaging; $B$, fluid attenuated inversion recovery; C, Tl-enhanced image). 
Table 2. Clinical features of 13 patients with Salmonella typhimurium brain abscess

\begin{tabular}{|c|c|c|c|c|c|c|}
\hline References & Year & Age/Sex & $\begin{array}{l}\text { Precipitating } \\
\text { factors }\end{array}$ & Symptoms and signs & Treatment modalities & Outcome \\
\hline $\begin{array}{l}\text { Paniker and } \\
\text { George }^{20)}\end{array}$ & 1965 & 30 months/F & Otitis & Fever, otorrhea & $\begin{array}{l}\text { Surgical drainage }+ \\
\text { antibiotics }\end{array}$ & Died \\
\hline Ellis et al. ${ }^{10)}$ & 1981 & 65 years $/ M$ & Meningitis & $\begin{array}{l}\text { Fever, headache, confusion, seizure, } \\
\text { hemiparesis, vomiting, diarrhea }\end{array}$ & Antibiotics & Died \\
\hline Iplikçioğlu et al. ${ }^{13)}$ & 1991 & 13 months/M & Unknown & Fever, seizure, vomiting & $\begin{array}{l}\text { Surgical drainage }+ \\
\text { antibiotics }\end{array}$ & Recovered \\
\hline Arentoft et al. ${ }^{3)}$ & 1993 & 59 years/F & Previous stroke & Seizure, hemiparesis & Antibiotics & Died \\
\hline Gueit et al. ${ }^{12)}$ & 1996 & 34 years $/ M$ & AIDS & Seizure, hemiparesis & Antibiotics & Recovered \\
\hline Smail et al. ${ }^{23)}$ & 1996 & 34 years $/ M$ & AIDS & $\begin{array}{l}\text { Fever, seizure, focal neurologic } \\
\text { deficit }\end{array}$ & Antibiotics & Recovered \\
\hline Lu et al. ${ }^{16)}$ & 1997 & 6 months/M & Unknown & $\begin{array}{l}\text { Fever, diarrhea, drowsiness, } \\
\text { convulsion }\end{array}$ & $\begin{array}{l}\text { Surgical excision }+ \\
\text { antibiotics }\end{array}$ & Recovered \\
\hline Broux et al. ${ }^{6}$ & 1998 & 56 years $/ M$ & Unknown & $\begin{array}{l}\text { Fever, septic shock, renal failure, } \\
\text { acute respiratory distress }\end{array}$ & Antibiotics & Recovered \\
\hline Kumari and Kan ${ }^{15)}$ & 2000 & 59 years $/ M$ & $\begin{array}{l}\text { Previous brain } \\
\text { operation }\end{array}$ & Fever, seizure, confusion & $\begin{array}{l}\text { Surgical drainage }+ \\
\text { antibiotics }\end{array}$ & Recovered \\
\hline Chadwick et al. ${ }^{7)}$ & 2004 & 54 years $/ M$ & $\begin{array}{l}\text { Alcoholic liver } \\
\text { disease }\end{array}$ & Fever, confusion & Antibiotics & Died \\
\hline Mohindra et al. ${ }^{19)}$ & 2014 & 5 months/M & Unknown & Fever, altered bowel habits & $\begin{array}{l}\text { Surgical drainage + } \\
\text { antibiotics }\end{array}$ & Recovered \\
\hline Ploton et al. ${ }^{21)}$ & 2017 & 3 months/M & Otitis & Fever, vomiting, seizure & Antibiotics & Recovered \\
\hline Present case & 2020 & 46 years $/ M$ & Previous ICH & Fever, hemiparesis, aphasia & $\begin{array}{l}\text { Surgical drainage }+ \\
\text { antibiotics }\end{array}$ & Recovered \\
\hline
\end{tabular}

F: female; M: male; AIDS: acquired immunodeficiency syndrome; $\mathrm{ICH}$ : intracerebral hemorrhage.

to the brain, 4 cases were in infants, 2 cases were in AIDS patients, one case involved alcoholism, 1 case had a previous stroke history, and the present case involved a previous ICH site (Table 2) $3,6,7,10-13,16,19,21,23)$.

Several factors contribute to the pathogenesis of salmonellosis: the Salmonella inoculum size, the virulence of the strain, the host immune response, and local protective factors ${ }^{22}$. Thus, Salmonella infection in humans shows a spectrum of symptoms from asymptomatic carriers to focal localized infections, such as meningitis, brain abscess, gastroenteritis, or cholecystitis, and sometimes even bacteremia ${ }^{8,22)}$. Likewise, the clinical presentations of Salmonella brain abscesses vary from simple headache or vomiting to altered states of consciousness or focal neurologic deficits.

Salmonella is a facultative intracellular organism, and a cellmediated immune response depends on macrophage function $^{2,9,24)}$. Increased susceptibility to Salmonella infection is thought to be due to several factors: prolonged exposure to the organism, impairment of the cell-mediated immune response, impairment of phagocytosis, alterations in local protective factors, and the presence of diseased tissue ${ }^{4,8,25)}$.

Determining the location and size of an abscess through CT and/or MRI and identifying the organism involved in pus culture is crucial for an accurate diagnosis and adequate treatment of brain abscess caused by Salmonella. Such abscess could be treated through surgical drainage and combined antibiotic therapy ${ }^{1,13,22)}$. In our review, almost all patients who died from brain abscesses caused by $S$. typhimurium did not undergo surgical drainage (Table 2). Chloramphenicol, a thirdgeneration cephalosporin, and trimethoprim/sulfamethoxazole are the drugs of choice after pus drainage. Salmonella strains resistant to these antibiotics are uncommon ${ }^{14,22)}$. In addition, long-term antibiotic therapy - at least 6 weeks - is essential because of the risk of recurrence. In our case, we administered ceftazidime, based on culture sensitivity, and vancomycin to prevent scalp and tract infections.

\section{CONCLUSION}

We report a rare case of an intracranial abscess caused by $S$. typhimurium at a previous spontaneous ICH site. Surgical drainage of the intracranial abscess and prolonged sensitive antibiotic therapy are essential to obtain positive results. In particular, we emphasize that early surgical drainage reduces mortality, as it prevents the unnecessary use of broad-spectrum antibiotics through pus culture. 


\section{CONFLICTS OF INTEREST}

No potential conflict of interest relevant to this article was reported.

\section{REFERENCES}

1. Akeda H, Mitsuyama M, Tatsukawa K, Nomoto K, Takeya K: The synergistic contribution of macrophages and antibody to protection against Salmonella typhimurium during the early phase of infection. J Gen Microbiol 123:209-214, 1981

2. Aliaga L, Mediavilla JD, López de la Osa A, López-Gómez M, de Cueto M, Miranda C: Nontyphoidal salmonella intracranial infections in HIV-infected patients. Clin Infect Dis 25:11181120, 1997

3. Arentoft H, Schønheyder H, Schønemann NK: Cerebral Salmonella typhimurium abscess in a patient with a stroke. Infection 21:251-253, 1993

4. Black PH, Kunz LJ, Swartz MN: Salmonellosis-a review of some unusual aspects. N Engl J Med 262:921-927 concl, 1960

5. Blaser MJ, Feldman RA: From the centers for disease control. Salmonella bacteremia: Reports to the centers for disease control, 1968-1979. J Infect Dis 143:743-746, 1981

6. Broux C, Santré C, Sirodot M, Allantaz F, Genin G, Bru JP: Cerebral abscess during a severe form of Salmonella typhimurium bacteremia in an immunocompetent patient. Presse Med 27:909-910, 1998

7. Chadwick D, Mitra T, Sitoh YY: Salmonella typhimurium brain abscess. Lancet 363:947, 2004

8. Cherubin CE, Neu HC, Imperato PJ, Harvey RP, Bellen N: Septicemia with non-typhoid salmonella. Medicine (Baltimore) 53:365-376, 1974

9. Collins FM, Mackaness GB, Blanden RV: Infection-immunity in experimental salmonellosis. J Exp Med 124:601-619, 1966

10. Ellis ME, Smith CC, Reid TM, Porter IA: Chloramphenicol-resistant Salmonella typhimurium meningitis in an adult. Br Med J (Clin Res Ed) 283:273, 1981

11. Glaser JB, Morton-Kute L, Berger SR, Weber J, Siegal FP, Lopez C, et al.: Recurrent Salmonella typhimurium bacteremia associated with the acquired immunodeficiency syndrome. Ann Intern Med 102:189-193, 1985

12. Gueit I, Bani-Sadr F, Borsa-Lebas F, Caron F, Langlois O, Hum- bert G: Salmonella typhimurium cerebral abscess in a patient with HIV infection. Presse Med 25:2052, 1996

13. Iplikçioğlu AC, Kökes F, Bayar MA, Edebali N, Gökçek C, Buharali Z: Brain abscess caused by Salmonella typhimurium. case report and review of the literature. J Neurosurg Sci 35:165168, 1991

14. Kinsella TR, Yogev R, Shulman ST, Gilmore R, Chadwick EG: Treatment of Salmonella meningitis and brain abscess with the new cephalosporins: Two case reports and a review of the literature. Pediatr Infect Dis J 6:476-480, 1987

15. Kumari P, Kan VL: Salmonella typhimurium brain abscess: postoperative complication. Clin Infect Dis 30:621-622, 2000

16. Lu CS, Chiu CH, Lin TY, Lin SL: Salmonella typhimurium brain abscess in a six-month-old infant: a case report and review of the literature. Changgeng Yi Xue Za Zhi 20:219-225, 1997

17. Mahapatra AK, Bhatia R: Salmonella intracerebral and subdural abscess--report of two cases. Postgrad Med J 63:373-375, 1987

18. Mahapatra AK, Pawar SJ, Sharma RR: Intracranial Salmonella infections: meningitis, subdural collections and brain abscess. A series of six surgically managed cases with follow-up results. Pediatr Neurosurg 36:8-13, 2002

19. Mohindra S, Savardekar A, Tripathi M, Raj A: Enlarging head size as the only presentation of Salmonella Typhimurium brain abscess in an infant: a short report. Br J Neurosurg 28:393-395, 2014

20. Paniker CK, George K: Otogenic brain abscess caused by Salmonella typhimurium. J Indian Med Assoc 45:451-452, 1965

21. Ploton MC, Gaschignard J, Lemaitre C, Cadennes A, Germanaud D, Poncelet G, et al.: Salmonella Typhimurium bacteraemia complicated by meningitis and brain abscess in a 3-month-old boy. J Paediatr Child Health 53:204-205, 2017

22. Rodriguez RE, Valero V, Watanakunakorn C: Salmonella focal intracranial infections: review of the world literature (1884-1984) and report of an unusual case. Rev Infect Dis 8:31-41, 1986

23. Smail A, Lafon B, Toussaint P, Masmoudi K, Leclerc N, Ducroix JP, et al.: Salmonella typhimurium cerebral abscess: rare complication of HIV infection. Presse Med 25:556, 1996

24. Suter E: Interaction between phagocytes and pathogenic microorganisms. Bacteriol Rev 20:94-132, 1956

25. Wolfe MS, Louria DB, Armstrong D, Blevins A: Salmonellosis in patients with neoplastic disease. A review of 100 episodes at Memorial Cancer Center over a 13-year period. Arch Intern Med 128:546-554, 1971 